\title{
Evaluation of Epoxy Resin Composites in Multilayer Structure for Stealth Technology
}

\author{
Tamara Indrusiak Silva1,2, *, Ketly Pontes Soares², laci Miranda Pereira², Loan Filipi Calheiros², Bluma \\ Guenther Soares ${ }^{2}$
}

\author{
Silva TI (D) https://orcid.org/0000-0002-1025-8537 \\ Soares KP (iD https://orcid.org/0000-0002-5836-7631 \\ Pereira IM (D) https://orcid.org/0000-0001-9595-1084 \\ Soares BG (D)ttps://orcid.org/0000-0002-1273-7574
}

How to cite

\begin{abstract}
Silva TI; Soares KP; Pereira IM; Calheiros LF; Soares BG (2019) Evaluation of Epoxy Resin Composites in Multilayer Structure for Stealth Technology. J Aerosp Technol Manag, 11, Special Edition: 37-40. https://doi.org/10.5028/jatm.etmq.23
\end{abstract}

\begin{abstract}
The present work evaluates a multilayer structure based on epoxy resin for stealth technology. The structure consists of two absorber layers with nanoferrite and a resistive layer between them containing polyaniline (PANI) with and without carbon nanotube (CNT). The best reflection loss result multilayer structure analyzed was Ni-PANICNT-Fe with RL $=-22 d B$ at $11,9 \mathrm{GHz}$, justified by higher conductivity loss due to the CNT in PANI epoxy composite.
\end{abstract}

KEYWORDS: Multilayer structure, Reflection loss, Conductivity loss.

\section{INTRODUCTION}

In recent years, radar absorbing materials (RAM) have attracted considerable attention due to their potential use in stealth technology, military radar, satellite and electronic equipment applications. Importantly, these materials must be absorbing electromagnetic energy over a wide frequency range while being adapted to protect the military object such as aircraft, submarines and armored vehicle from enemy radar detection (Choi and Jung 2015). In addition, they must be lightweight, corrosion resistant, strongly absorbed over a wide frequency range and have mechanical strength (Zhou et al. 2018). To develop such materials, multilayer structures composed of magnetic and dielectric particles have been studied in order to meet such properties (Moitra et al. 2017). In the present work, the microwave absorption properties of a triple layer system of epoxy resin composites, consisting of two absorptive layers with magnetic charges and, between them, a dielectric layer, was carried out to be used in stealth technology.

\section{EXPERIMENTAL}

To obtain the dielectric charges, the synthesis of pure polyaniline (PANI) was performed with and without carbon nanotube (CNT) (Calheiros et al. 2017). For magnetic charges, nanoferrites were synthesized (Oliveira et al. 2017). Subsequently, the dispersion of the charges on the epoxy resin was performed. For dielectric materials, a ratio of 80/20 wt \%, Epoxy/PANI with and without the presence of CNT (PANICNT) was established. Magnetic charges were also dispersed in epoxy resin in the proportion of 94/6 wt\%, Epoxy / Ferrite, using $\mathrm{NiFe}_{2} \mathrm{O}_{4}(\mathrm{Ni})$ and $\mathrm{Fe}_{3} \mathrm{O}_{4}(\mathrm{Fe})$ nanoferrites.

\footnotetext{
1.Centro Tecnológico do Exército, Laboratório de Materiais, Rio de Janeiro/RJ - Brasil

2.Universidade Federal do Rio de Janeiro, Departamento de Engenharia Metalúrgica e de Materiais, Rio de Janeiro/RJ - Brasil

*Correspondence author: tammy.indrusiak@gmail.com

Received: 27 Nov 2019 | Accepted: 10 Dec 2019

Note: This paper was selected from the 10 Encontro Técnico de Materiais e Química (ETMQ) ocurred in 27-29 november of 2019 and organized by Instituto de Pesquisas da Marinha (IPqM) in Rio de Janeiro/RJ, Brazil
} 
For characterization of the monolayers, reflectivity (RL), real $\left(\varepsilon^{\prime}\right)$ and complex $\left(\varepsilon^{\prime \prime}\right)$ permittivity, and real $\left(\mu^{\prime}\right)$ and complex $\left(\mu^{\prime \prime}\right)$ permeability were obtained from the network vector analyzer (VNA) model. Agilent N5230C PNA-L, X-Band (8.2 to 12.4GHz), with dimensions of $22 \times 10 \times 1 \mathrm{~mm}$. Then two multilayer structures were assembled, as shown in Fig. 1, where the ferrite layers are called absorber layers and the PANI layer are the resistive layers. With these structures, the reflectivity, also measured in the VNA (Fig. 2), and its respective percentages of absorbed energy $\left(\mathrm{E}_{\mathrm{a}}\right)$ were obtained.

(a)

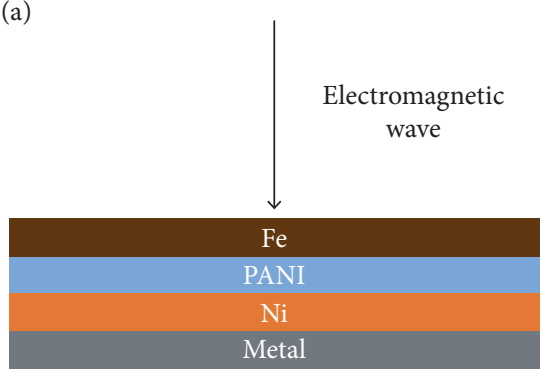

(b)

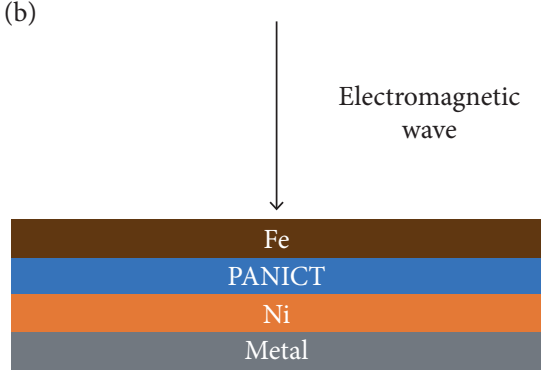

Figure 1. Multilayer structure: (a) PANI and (b) PANICNT as dielectric layers.

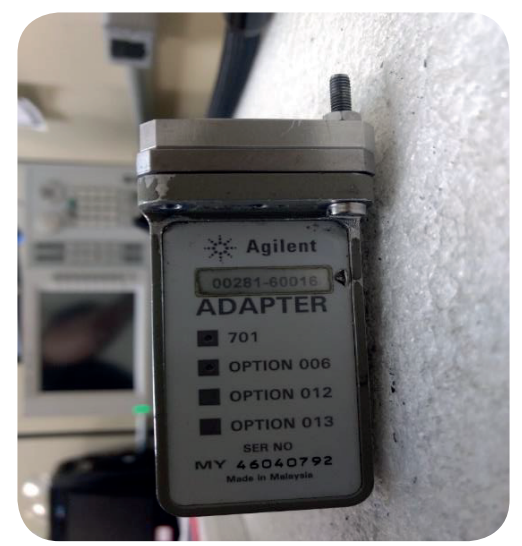

Figure 2. Set up for RL measurement.

\section{RESULTS}

Figure 3 shows the permittivity and permeability results for the monolayers. For the dielectric samples, the permittivity values (Fig. 3a) were justified by the mechanisms generated through the interaction of the charges with the electric field, such as conductivity, dipole and interfacial polarizations and relaxations. It was observed that those properties for PANICNT are higher in relation to PANI, which may be justified by the presence of CNT that promotes more interfacial polarizations than only PANI. For ferrite composites, the values are similar for $\mathrm{Fe}$ and Ni permeability, caused by the natural resonance of nanoferrites (Fig. 3b).

Figure 4 presents the RL for the monolayers and Fig. 5 for the multilayer where they were assembled based on the study by Choi and Jung (2015), where a resistive layer is placed between two absorbent layers. The absorbing layer was placed in contact with air due to impedance matching that promotes wave penetration in material and minimizes reflection at the interface. The second layer is resistive, which promotes conduction loss, further increasing absorption. The third layer also promotes absorption, since the residual energy that has been transmitted to the last layer will be fully absorbed.

Figure 4 shows that PANICNT had the worst performance, since the added CNT may have improved matrix conductivity. The best performing monolayers were Ni with RL of $-5.5 \mathrm{~dB}\left(\mathrm{E}_{\mathrm{a}}=74 \%\right)$ at $8.5 \mathrm{GHz}$ and PANI with $-4 \mathrm{~dB}\left(\mathrm{E}_{\mathrm{a}}=60 \%\right)$ at $11.5 \mathrm{GHz}$. 
(a)

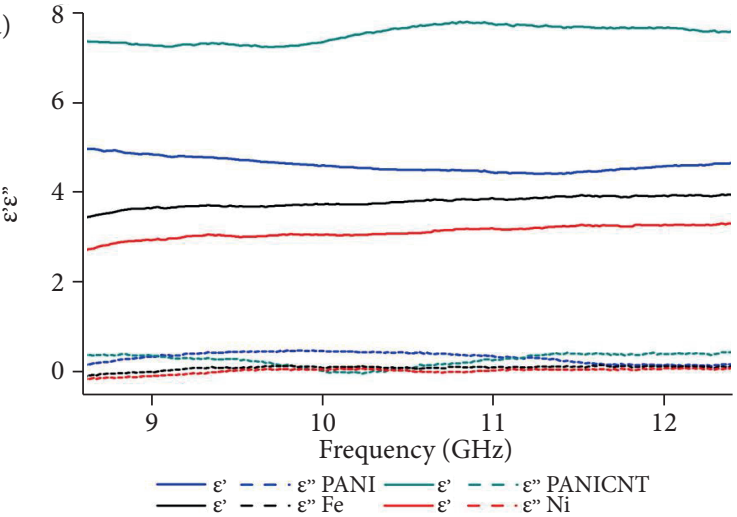

(b)

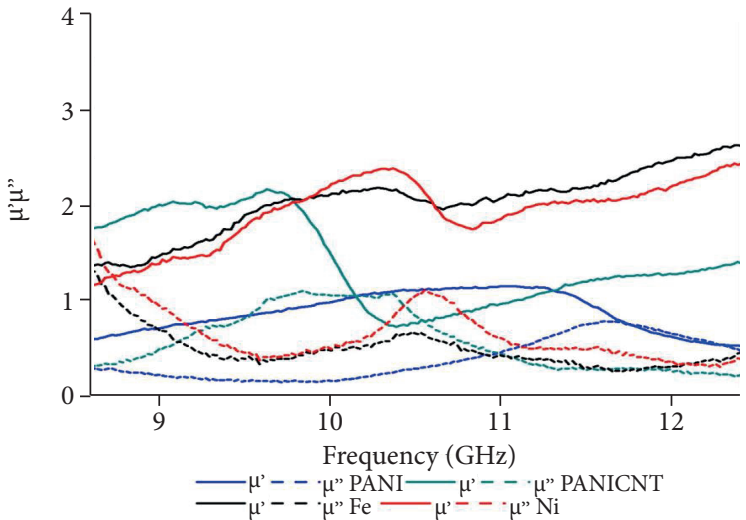

Figure 3. Results of monolayer (a) permittivity and (b) permeability.

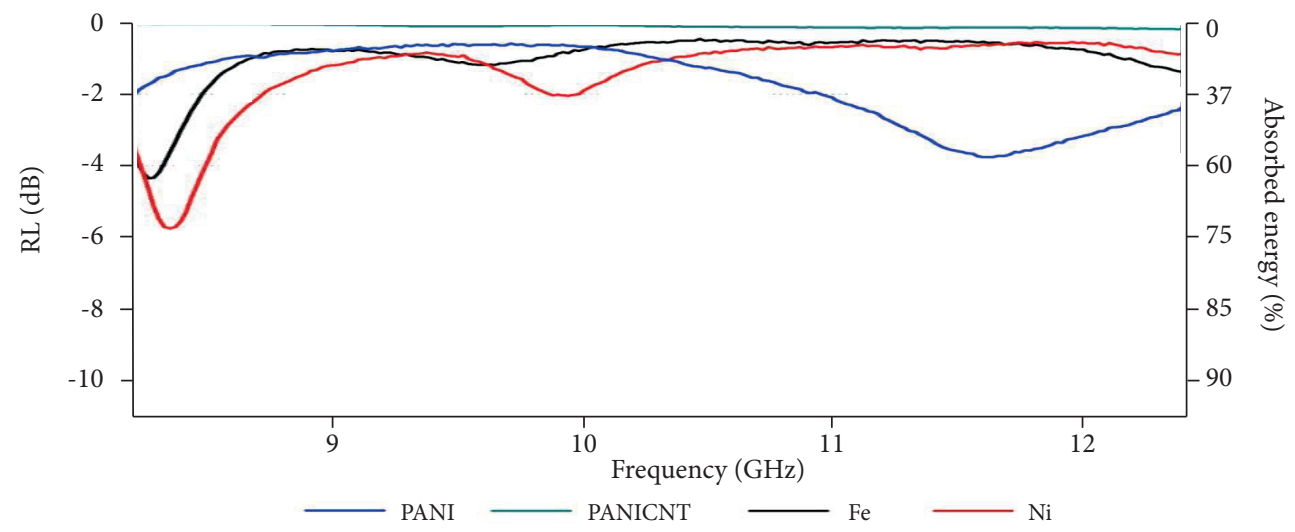

Figure 4. RL for monolayers

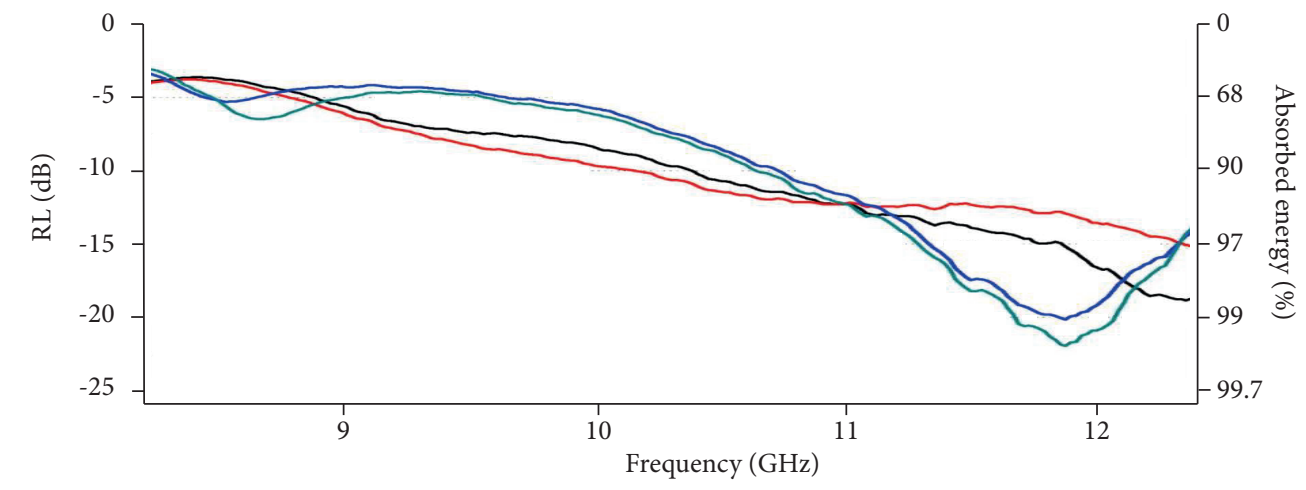

Figure 5. RL for multilayer structures.

The values shown are low due to the amount of load added, requiring other resources to improve attenuation. To this end, a multilayer system was assembled so that it can increase the absorption of the material (Fig. 1).

Figure 5 shows that RL values increased considerably compared to monolayers. It was found that the order of the absorber layers slightly increases the value of RL, depending on the resistive layer between them; for example, when the resistive layer is PANI and Fe is in contact with air, $\mathrm{RL}=-16\left(\mathrm{E}_{\mathrm{a}}=97 \%\right)$ at $12.4 \mathrm{GHz}$, and when the resistive layer is PANICNT and Ni in contact with air, a $\mathrm{RL}=-22 \mathrm{~dB}\left(\mathrm{E}_{\mathrm{a}}=99.1 \%\right)$ at $11.9 \mathrm{GHz}$ was obtained, emphasizing that the multilayer structure is a broadband 
frequency. This result may be justified by the presence of CNT, which presents dielectric charges as it promotes greater energy dissipation through ohmic loss, and transfers this energy to the free electrons, so that it can move within the material, increasing the conduction loss. Moreover, PANICNT generates greater number of interfacial polarizations and, consequently, creates more multiple internal reflections at boundaries that further promote wave absorption, as observed by Najim et al. (2015). Thus, this epoxy resin multilayer system has great potential for use in stealth technology.

\section{CONCLUSION}

The results showed the effect of an epoxy matrix in multilayer structure on absorbing properties with application in stealth technology. Monolayer results showed that the Ni-particle matrix had an RL of $-5.5 \mathrm{~dB}$ at $8.5 \mathrm{GHz}$. The multilayer Ni-PANICNT-Fe structure obtained the best result of $\mathrm{RL}=-22 \mathrm{~dB}$ at $11.9 \mathrm{GHz}$, which is a promising result to be used in this technology.

\section{FUNDING}

Fundação Carlos Chagas Filho de Amparo à Pesquisa do Estado do Rio de Janeiro [http://dx.doi.org/10.13039/501100004586]

Fundação de Amparo à Pesquisa do Estado de Minas Gerais [http://dx.doi.org/10.13039/501100004901]

Conselho Nacional de Desenvolvimento Científico e Tecnológico [http://dx.doi.org/10.13039/501100003593]

\section{AUTHORS’ CONTRIBUTION}

Conceptualization, Silva TI; Methodology, Calheiros LF and Soares KP; Research, Silva TI and Soares BG; Writing - First version, Silva TI; Writing - Review \& Editing, Pereira IM and Soares BG; Resources, Calheiros LF and Soares KP; Supervision, Soares BG.

\section{REFERENCES}

\footnotetext{
Calheiros LF, Soares BG, Barra GMO (2017) DBSA-CTAB mixture as the surfactant system for the one step inverse emulsion polymerization of aniline: Characterization and blend with epoxy resin. Synth Met 226:139-147. https://doi.org/10.1016/j.synthmet.2017.02.014

Choi J, Jung H-T (2015) A new triple-layered composite for high-performance broadband microwave absorption. Compos Struct 122:166171. https://doi.org/10.1016/j.compstruct.2014.11.020

Moitra D, Dhole S, Ghosh BK, Chandel M, Jani RK, Patra MK, Vadera SR, Ghosh NN (2017) Synthesis and Microwave Absorption Properties of $\mathrm{BiFeO3}$ Nanowire-RGO Nanocomposite and First-Principles Calculations for Insight of Electromagnetic Properties and Electronic Structures. J Phys Chem C 121(39):21290-21304. https://doi.org/10.1021/acs.jpcc.7b02836

Najim M, Smitha P, Agarwala V, Singh D (2015) Design of light weight multi-layered coating of zinc oxide-iron-graphite nano-composites for ultra-wide Bandwidth microwave absorption. J Mater Sci: Mater Eletron 26(10):7367-7377. https://doi.org/10.1007/s10854015-3366-8

Oliveira AR, Abrishamkar A, Veloso EM, Oliveira FC, Silva JG, Pereira JR, Diniz R, Denadai AML (2017) Effect of composition on rheological behavior of iron oxides produced by hydrothermal method. Ceram Int 43(10):7436-7442. https://doi.org/10.1016/j. ceramint.2017.03.005

Zhou J, Chen Y, Li H, Dugnani R, Du Q, UrRehman H, Kang H, Liu H (2018) Facile synthesis of three-dimensional lightweight nitrogendoped graphene aerogel with excellent electromagnetic wave absorption properties. J Mater Sci 53(6):4067-4077. https://doi. org/10.1007/s10853-017-1838-3
} 